\title{
A solid-state NMR study of structure and segmental dynamics of semicrystalline elastomer-toughened nanocomposites
}

\author{
Jiri Brus*, Martina Urbanová, Ivan Kelnar, Jiří Kotek
}

\section{Supporting information}

The adequate setup of the AM-PISEMA recoupling sequence requires: $i$ ) optimization of FSLG decoupling power level, and ii) setup of Hartmann-Hahn matching condition at $+/-1$

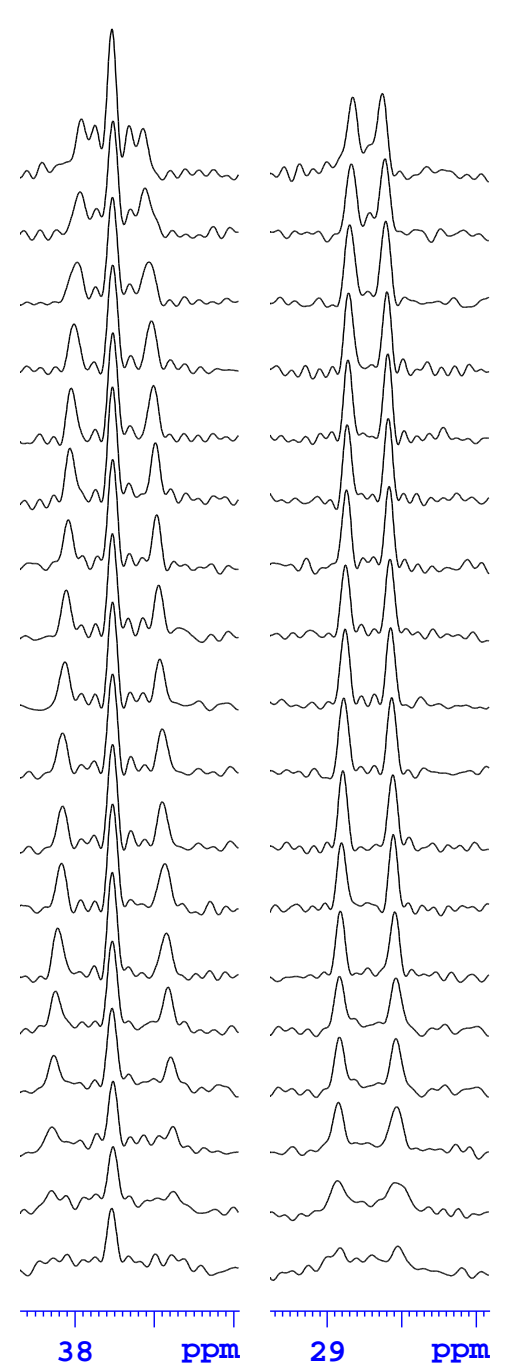

Figure S1. Optimization of power level of FSLG decoupling $\mathrm{B}_{1}\left({ }^{1} \mathrm{H}\right)$ at selected ${ }^{1} \mathrm{H}$ offset $(75 \mathrm{kHz})$. spinning side bands.

i) FSLG decoupling requires optimization of power level of $\mathrm{B}_{1}\left({ }^{1} \mathrm{H}\right)$ field at selected ${ }^{1} \mathrm{H}$ offset (e.g. $75 \mathrm{kHz}$ ). Setup is performed on adamantane, and the aim is to reach the splitting between signals corresponding to the scaled ${ }^{1} J_{\mathrm{CH}}$ coupling constants in $\mathrm{CH}$ and $\mathrm{CH}_{2}$ groups.

ii) Applying the obtained power level and frequency offset of $\mathrm{B}_{1}\left({ }^{1} \mathrm{H}\right)$ field, a power level of $\mathrm{B}_{1}\left({ }^{13} \mathrm{C}\right)$ field is optimized to find Hartmann-Hahn matching conditions i.e. to find +/- 1 spinning side band matching maxima. Optimization is performed on alanine.

All these parameters, offset and power level of $\mathrm{B}_{1}\left({ }^{1} \mathrm{H}\right)$ field, and both power levels of $\mathrm{B}_{1}\left({ }^{13} \mathrm{C}\right)$, are then applied for the recoupling sequence.

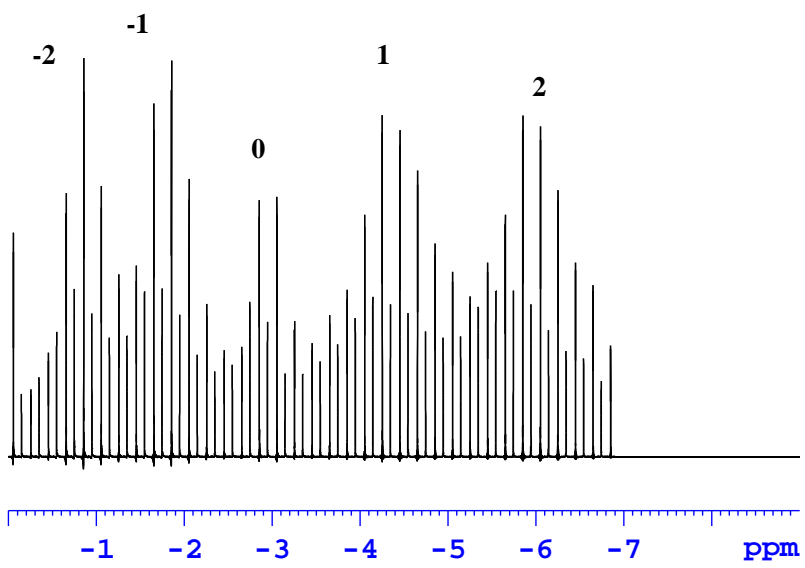

Figure S2. Optimization of power level of LGCP at selected ${ }^{1} \mathrm{H}$ offset $(75 \mathrm{kHz})$ and power level of $\mathrm{B}_{1}\left({ }^{1} \mathrm{H}\right)$ field. Setup of Hartmann-Hahn matching condition at $+/-1$ spinning side band. 


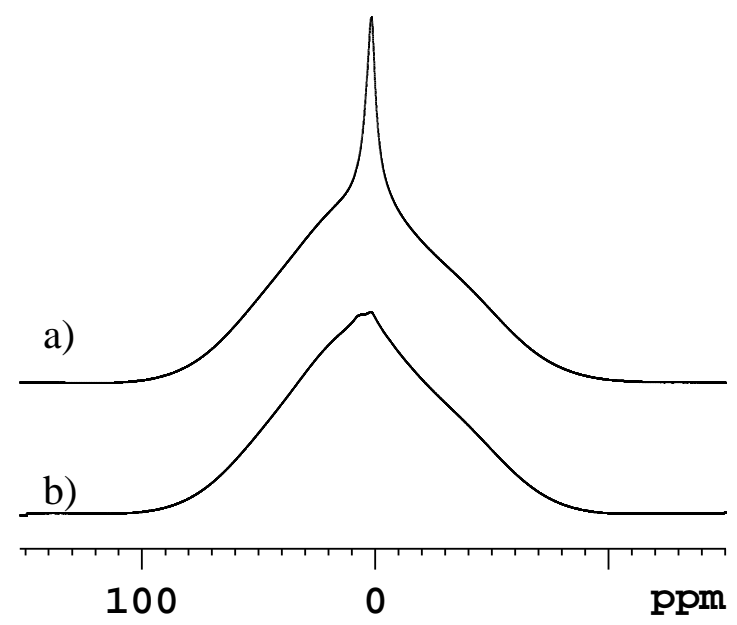

Figure S3. ${ }^{1} \mathrm{H}$ NMR spectra of nanocomposites of polyamide-6: NC/EMA (a), and NC (b). Phase-separated EMA copolymer is reflected by the narrow signal.

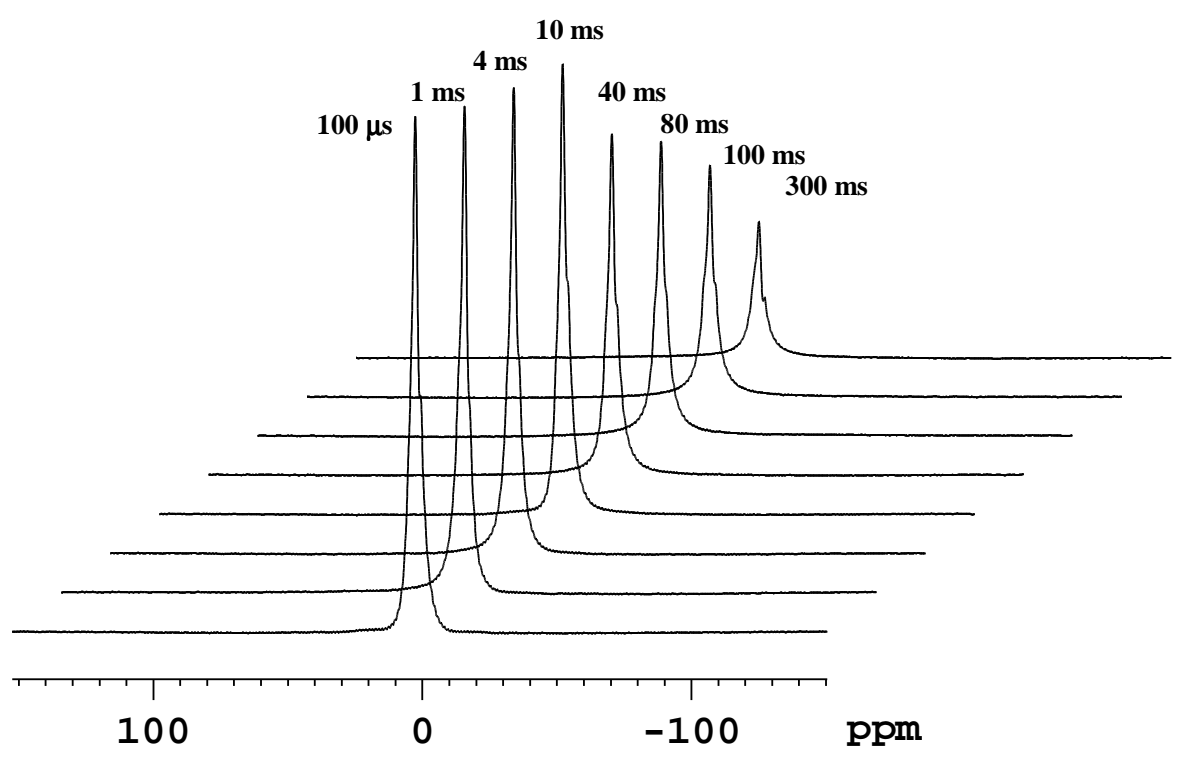

Figure S4. Goldman-Shen experiment (Goldman, M.; Shen, L. Phys Rev 1966, 144, 321) performed on nanocomposite NC/EMA. Dipolar-dephasing period for the selection of magnetization of mobile fraction (EMA) was $80 \mu \mathrm{s}$. The spin diffusion period varied from $100 \mu$ s to $300 \mathrm{~ms}$. No significant increase in the intensity of the broad signal of PA6 was detected within $10 \mathrm{~ms}$. Equilibration of magnetization was not achieved even after $300 \mathrm{~ms}$. At these long spin-diffusion periods $T_{1}\left({ }^{1} \mathrm{H}\right)$ relaxation becomes dominant process affecting magnetization evolution. 


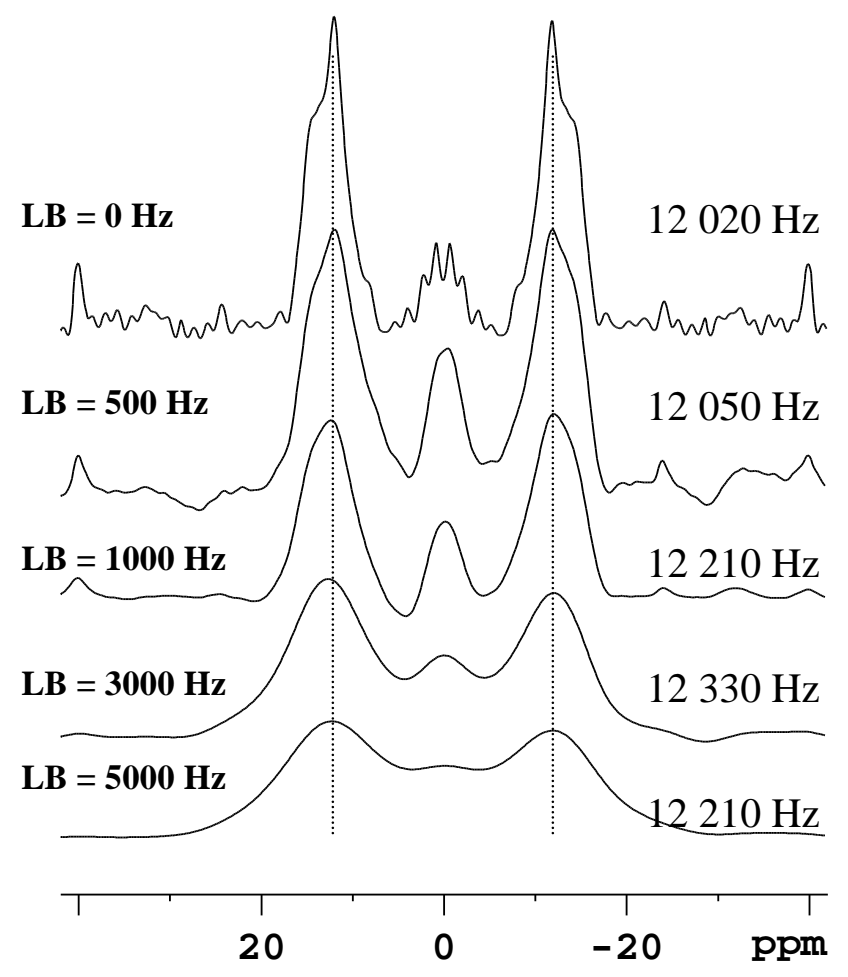

Figure S5. ${ }^{13} \mathrm{C}-\left\{{ }^{1} \mathrm{H}\right\}$ dipolar spectra of $\mathrm{CH}_{2}$ unit of glycine artificially broadened by LB parameter (line broadening) during the processing of the experimentally determined dipolar data. The splitting of the dipolar spectra $(\Delta v)$ is shown at the right side, and the corresponding LB parameter at the left side of each spectrum. 
CH

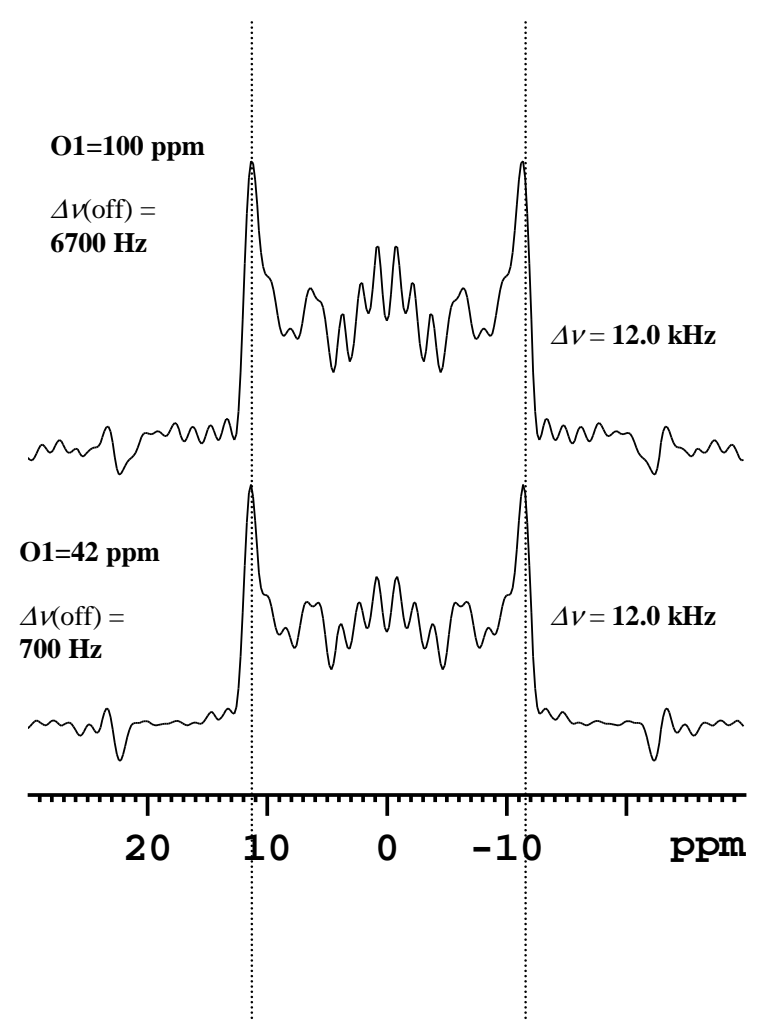

$\mathrm{CH}_{3}$

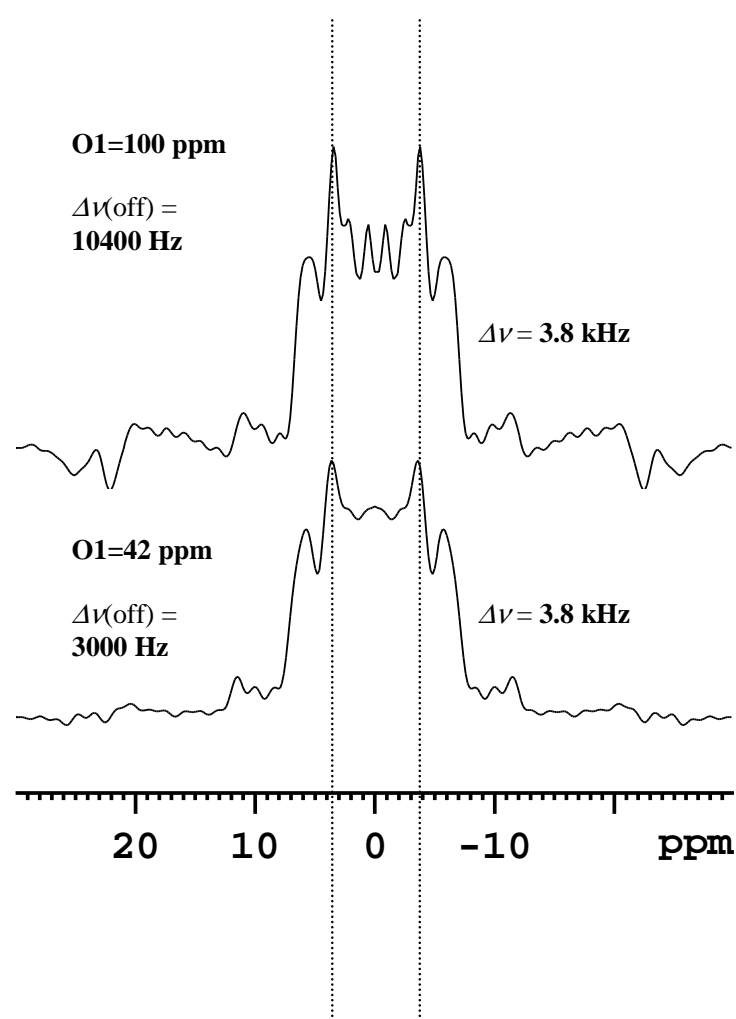

Figure S6. ${ }^{13} \mathrm{C}-\left\{{ }^{1} \mathrm{H}\right\}$ dipolar spectra of $\mathrm{CH}$ and $\mathrm{CH}_{3}$ units of uniformly labeled alanine measured with various ${ }^{13} \mathrm{C}$ resonance offset. The splitting of the dipolar spectra $(\Delta v)$ is shown at the right side, and the corresponding ${ }^{13} \mathrm{C}$ resonance offset at the left side of each spectrum (O1 - offset of ${ }^{13} \mathrm{C}$ carrier frequency in ppm, $\Delta \nu$ (off) - difference of the carrier frequency and the corresponding ${ }^{13} \mathrm{C}$ NMR signal in $\mathrm{Hz}$. 